\title{
SMART FARMING: IOT Based Smart Sensor Agriculture Stick for Live Temperature and Humidity Monitoring
}

\author{
Nirav Rathod \\ K. J. Somaiya Institute of Engineering \& Information \\ Technology University of Mumbai, India
}

\author{
Shreedhar Panigrahi \\ K. J. Somaiya Institute of Engineering \& Information \\ Technology University of Mumbai, India
}

\author{
Vijaya Pinjarkar \\ K. J. Somaiya Institute of Engineering \& Information Technology \\ University of Mumbai, India
}

\begin{abstract}
Internet of Things (IoT) technology has evolved in each and every field of common man's life by making everything smart and intelligent. IoT refers to a network of things which make a self-configuring network. The development of various different Intelligent Smart Farming IoT based devices is day by day changing the face of agriculture which helps in production of crops by not only upgrading it but also making it cost-effective and reducing wastage. These paper is to propose a Smart IoT based Agriculture Stick that will farmers in getting live Data of Temperature, Soil Moisture, etc and other factors for efficient environment monitoring which will help them to do smart farming and increase their overall yield and quality of products. The Agriculture stick being proposed through this paper is integrating with Arduino Technology, Breadboard and mixed with different various sensors and live data feed can be obtained online through mobile phone. The product being proposed is tested on Live Agriculture Fields giving high accuracy in data feeds in different soil condition at different locations.
\end{abstract}

Keywords-Internet of Things (IoT), Agriculture, Agriculture IoT, Agriculture Precision, Arduino Mega 2560, Temperature Sensor, Smart Farming, Soil Moisture Sensor

\section{INTRODUCTION}

The next era of Smart Computing will be based on the Internet of Things (IoT). The Internet of Things (IoT), these days is playing a crucial role in transforming "Traditional Technology" from homes to offices to "Next Generation Everywhere Computing". One of the main areas where IoT based research is going on and new products are launching on an everyday basis to make the activities smarter and efficient towards better production is in the field of "Agriculture". Agriculture sector is regarded as the most crucial sector globally for ensuring food security. Speaking of India farmers, they are right now in huge trouble, a disadvantageous position in farm size, technology, trade, government policies, climate conditions etc. Agricultural production requires lots of activities like soil and plant monitoring, environmental monitoring like moisture and temperature, transportation, supply chain management, infrastructure management, control systems management, animal monitoring, pest control etc. Monitoring the environmental factors is not the complete solution to increase the yield of crops. There are a number of other factors that decrease productivity to a greater extent.

Hence, automation must be implemented in agriculture to overcome these problems. So, in order to provide a solution to all such problems, it is necessary to develop an integrated system which will take care of all factors affecting the productivity in every stage. But complete automation in agriculture is not achieved due to various issues. Though it is implemented in the research level and it is not given to the farmers as a product to get benefited from the resources. Hence this paper deals about developing smart agriculture using IoT Devices which can be used by farmers.

In India, the projected population by 2050 is considered as approx. 1500 million and agriculture remaining their primary source of living in rural areas, the focus should be on the increase of agricultural productivity. Though our country claims that they have developed in the field of science and technology, erratic power supply or complete breakdown of electricity for many hours together has almost become routine today. Use of Solar power is increasing today worldwide as a renewable source of energy. India has huge untapped solar off-grid opportunities. The main advantage of this project is optimizing the power usage through water resource management and also saving the government's free subsidiary electricity. This proves an efficient and economic way of irrigation and this will help in automating the agriculture sector.

\section{LITERATURE REVIEW}

In [1] K. Lakshmisudha et. al, "Smart Precision Based Agriculture Using Sensors"; It focuses on developing devices and tools to manage, display and alert the users using the advantages of a wireless sensor network system. 
In [2] Sushanth \& G. Sujatha, "IoT Based Smart Agriculture"; The paper aims at making use of evolving technology i.e. IOT and smart agriculture using automation. Monitoring environmental conditions is the major factor to improve yield of efficient crops. The feature of this paper includes development of a system which can monitor temperature, humidity, moisture and even the movement of animals which may destroy the crops in agricultural fields through sensors using an Arduino board.

In [3] M.K.Gayatri \& J.Jayasakthi, "Providing Smart Agriculture Solutions to Farmers for Better Yielding Using IoT"; The cloud computing devices that can create a whole computing system from sensors to tools that observe data from agricultural field images and from human actors on the ground and accurately feed the data into the repositories along with the location as GPS coordinates.

In [4] Chetan Dwarkani $M$ et. al, "Design and Development of Precision Agriculture System Using Wireless Sensor Network"; This idea proposes a novel methodology for smart farming by linking a smart sensing system and smart irrigator system through wireless communication technology.

In [5] Dr. V.Vidya Devi \& G. Meena Kumari, "Real-Time Automation and Monitoring System for Modernized Agriculture"; It proposes an idea about how an automated irrigation system was developed to optimize water use for agricultural crops. In addition, a gateway unit handles sensor information.

In [6] S. R. Nandurkar et. al, "Agricultural Protection System Based on IoT"; It is designed for an IoT based monitoring system to analyze crop environments and the method to improve the efficiency of decision making by analyzing harvest statistics.

In [7] Monika Jhuria et. al, "Image Processing for Smart Farming: Detection of Disease and Fruit Grading"; In this paper image processing is used as a tool to monitor the diseases on fruits during farming, right from plantation to harvesting. The variations are seen in color, texture and morphology.

In [8] Ms. Shraddha \& Ashok Ku. Maurya, "IOT Based Agriculture"; E-system delineates details about the design and implementation of variable rate irrigation and wireless sensor network and on field sensing in real time and controlling the design and implementation by using appropriate software. The whole system was developed using five in field sensor stations which collect the data and send it to the base station using a global positioning system (GPS) where necessary action was taken for controlling irrigation according to the database available with the system.

In [9] Ms. Roopashree V. et. al, "IOT in Indian Agriculture using Wireless sensor"; The project is mainly related with off-grid application. The objective is to supply water to the fields by using solar power as the main source. In this the user can water fields and protect his crops from anywhere by using GSM technique.

\section{PROPOSED SYSTEM}

\section{A. BASIC BLOCK DIAGRAM:}

In fig. 1 block diagram of the system is shown. It uses a raspberry pi 2 . The sd card for storing the notices is connected to the raspberry pi. The raspberry is connected to the wifi using ethernet. Hdmi acts as the interface between the lcd and the raspberry pi.

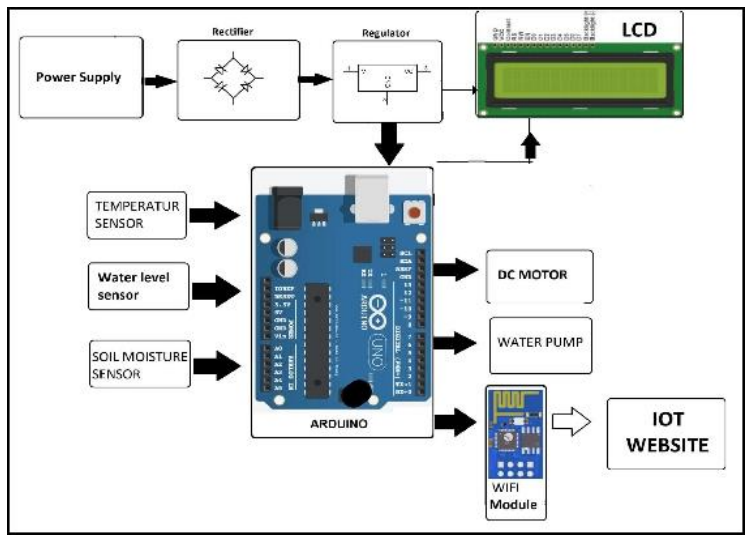

Fig. 1. block diagram of the proposed system

\section{B. BLOCK WISE WORKING:}

When the power supply is switched on, the GSM modem gets initialized. The GSM modem communicates with the ARM LPC 2148 board using AT commands. The LCD display is connected to the ADC pins of the ARM processor, in order to display the message. The humidity sensor checks for the soil moisture content whose maximum threshold is kept at $1000 \mathrm{oc}$ and minimum of $300 \mathrm{oc}$. When the soil moisture content is less than $300 \mathrm{oc}$ the pump motor will pump the water to the filed. The temperature sensor will measure the surrounding temperature of the farm. The rain sensor will sense the heavy rain and closes the panel to protect the crop. All the above information will be informed to the user using GSM technology.

\section{HARDWARE COMPONENTS:}

The hardware components which will perform all these functions are:

\section{a. NODE MCU CHIP:}

NodeMCU is a low-cost open source IoT platform. It initially included firmware which runs on the ESP8266 Wi-Fi SoC from Espressif Systems, and hardware which was based on the ESP-12 module. Later, support for the ESP32 32-bit MCU was added. The prototyping hardware typically used is a circuit board functioning as a dual in-line package (DIP) 
which integrates a USB controller with a smaller surface-mounted board containing the MCU and antenna. The design was initially was based on the ESP-12 module of the ESP8266, which is a Wi-Fi SoC integrated with a Tensilica Xtensa LX106 core, widely used in IoT applications

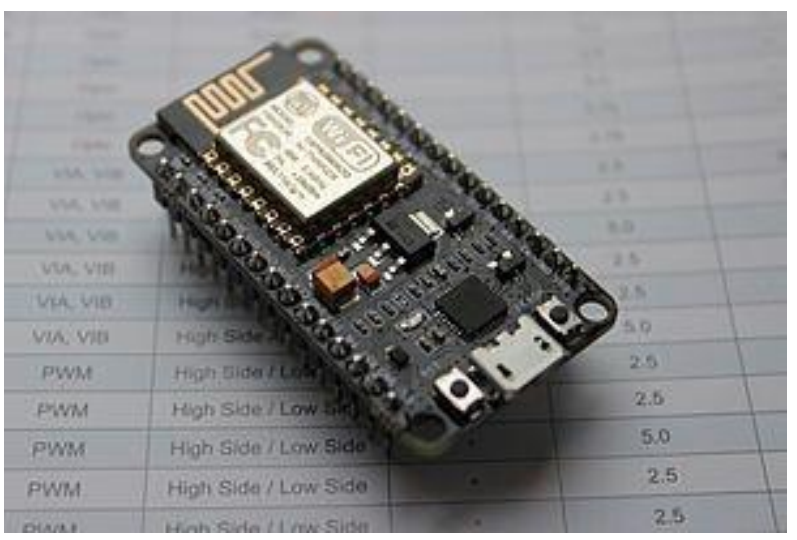

Fig. 2. NODE MCE chip

\section{b. GSM MODULE:}

GSM Modem can accept any GSM network operator SIM and it can act just like a mobile phone with its own unique phone number. The necessity to use this is it can use RS-232 protocol which can be easily connected to the controller. It can be used like a phone where it can send and receive SMS and make a call. The GSM modem is connected to the controller through RS232. The SMS is sent through the terminal to the number using AT Commands. The security strategies standardized for the GSM system make it the most secure telecommunications standard currently accessible. Although the confidentiality of a call and secrecy of the GSM subscriber is just ensured on the radio channel, this is a major step in achieving endto- end security.

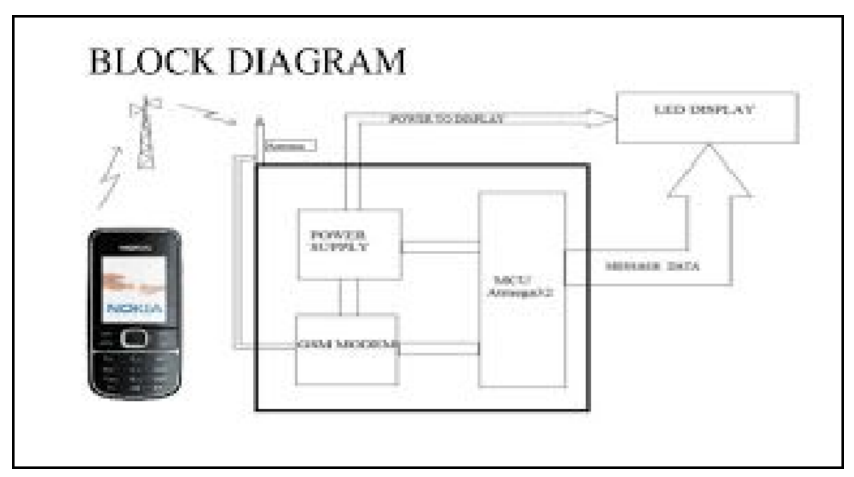

fig. 3. GSM Module

\section{c. SOIL MOISTURE SENSOR:}

Soil moisture sensor is a sensor which senses the moisture content of the soil. The sensor has both the analog and the digital output. The digital output is fixed and the analog output threshold can be varied. It works on the principle of open and short circuit. The output is high or low indicated by the LED. When the soil is dry, the current will not pass through it and so it will act as an open circuit. Hence the output is said to be maximum. When the soil is wet, the current will pass from one terminal to the other and the circuit is said to be short and the output will be zero.

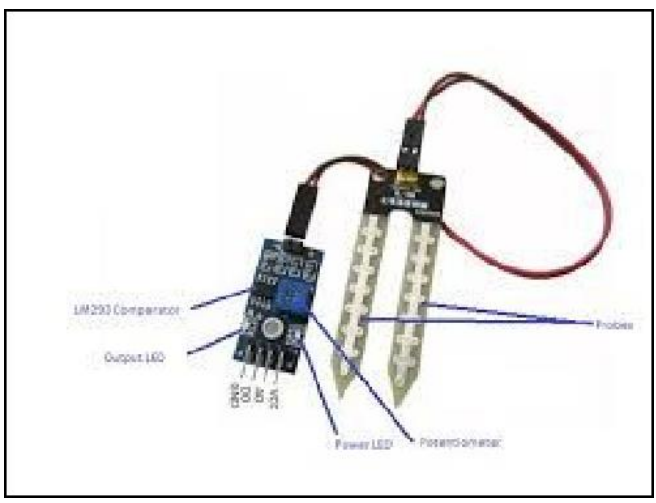

Fig. 3. Soil Moisture Sensor

\section{d. TEMPERATURE SENSOR:}

The LM 35 sensor is highly used because its output voltage is linear with the Celsius scaling of temperature. It does not provide any external trimming. It has a wide operating range. The maximum output is $5 \mathrm{~V}$. It consumes a minimum amount of electricity. Thus, it is energy efficient. It is very efficient in horticulture. It is user friendly to use. The most common type of temperature sensor is a thermometer, which is used to measure temperature of solids, liquids and gases. It is also a common type of temperature sensor mostly used for nonscientific purposes because it is not so accurate. Temperature sensors are used in many applications like HVand AC system environmental controls, food processing units, etc.

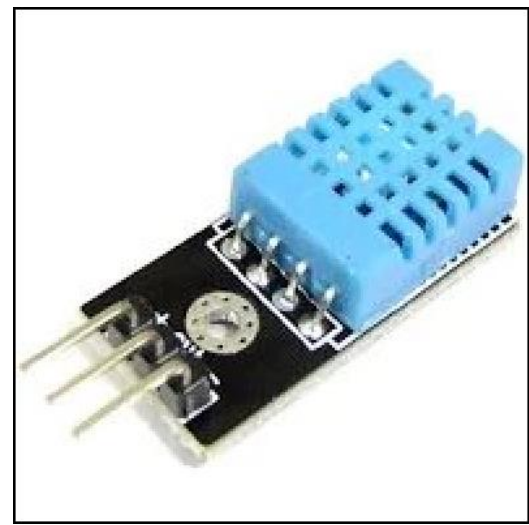

Fig. 4. Temperature Sensor

\section{e. PIR SENSOR:}

All objects with a temperature above absolute zero emit heat energy in the form of radiation. It is invisible to the human eye since it radiates infrared wavelengths. PIR sensors don't detect or measure heat, instead they detect the infrared radiation emitted or reflected from an object. It is used to detect the movement of people, animals or other objects. When a human passes in the field, the temperature at that point will rise from 
room temperature. The sensor converts the resulting change into a change in the output voltage and this triggers the detection.

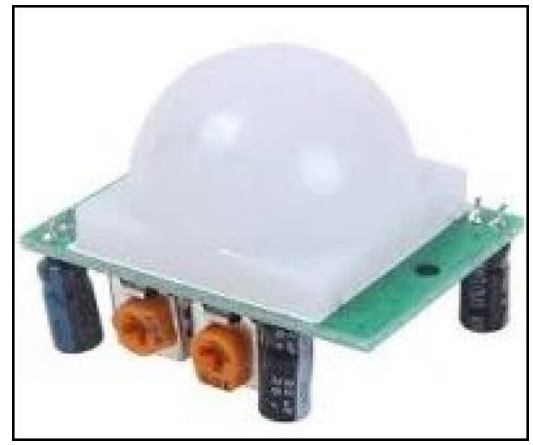

Fig. 5. PIR Sensor

\section{f. LIGHT SENSOR:}

A light dependent resistor also known as a photoresistor or photoconductor or photocell, is a resistor whose resistance depends on light intensity. LDR's are light sensitive devices. The light sensor is a passive device that converts this "light energy" whether visible or in the infra-red parts of the spectrum into an electrical signal output. Light sensors are more commonly known as "Photoelectric Devices" or "Photo Sensors" because they convert light energy (photons) into electricity (electrons). Photoelectric devices can be grouped into two main categories, those which generate electricity when illuminated, such as Photo-voltaics or Photo-emissives etc, and those which change their electrical properties in some way such as Photo-resistors or Photo-conductors. This leads to the following classification of devices.

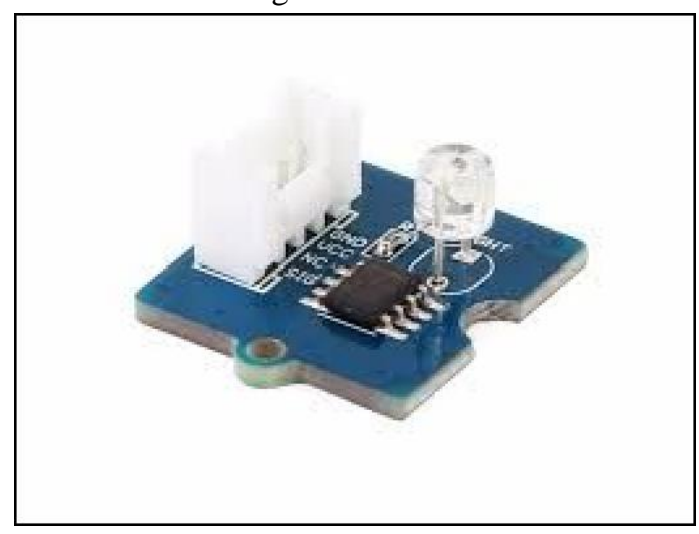

Fig. 6. Light Sensor

\section{g. Wi-Fi MODULE:}

The ESP8266 Wi-Fi Module is an independent system on chip with built-in TCP/IP protocol stack which allows the microcontroller to access the Wi-Fi network. The ESP8266 has the potential of either hosting an application or discharging the Wi-Fi networking functions entirely from an additional application processor. This module has a powerful enough on-board processing and storage capability that allows it to be integrated with the sensors and other application specific devices through its GPIOs with minimal development up-front and minimal loading during runtime.

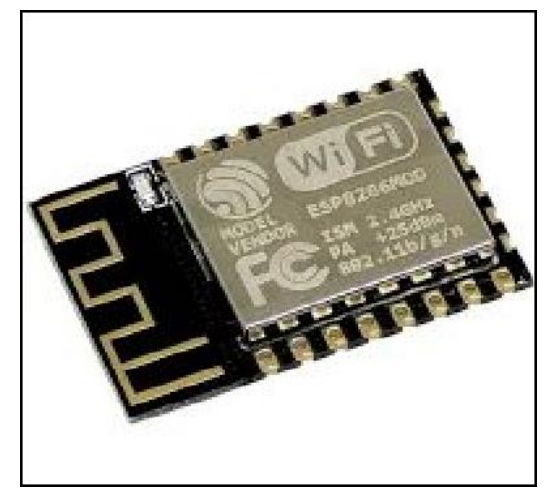

Fig. 7. Wi-Fi Module

\section{SOFTWARE USED:}

Arduino IDE is an open-source software program that allows users to write and upload code within a real-time work environment and upload it to the board. As this code will thereafter be stored within the cloud, it is often utilised by those who have been searching for an extra level of redundancy.The Environment is written in Java and based on Processing and other open-source software. The system is fully compatible with any Arduino software board.

\section{METHODOLOGY}

In the Recent era of IoT, many new research has been conducted in terms of Smart IoT based product's development which will help farmers in Smart Farming in terms of Managing Crop, Pest Control, Agriculture Precision, Agriculture Fields Monitoring through different Sensors and even Drones. In this part, Smart IoT based Agricultural stick is being developed for live monitoring of Temperature, Moisture using Arduino and various other electrical components. The temperature sensor senses the surrounding temperature of the farm in different farm conditions. When raining is observed by the sensor, the pump motor will stop pumping the water to the field and updates the user using GSM/GPRS technique. When there is an unconditional rain the panels provided will be closed automatically to protect the crop. An Alphanumeric LCD is used to display the data. 


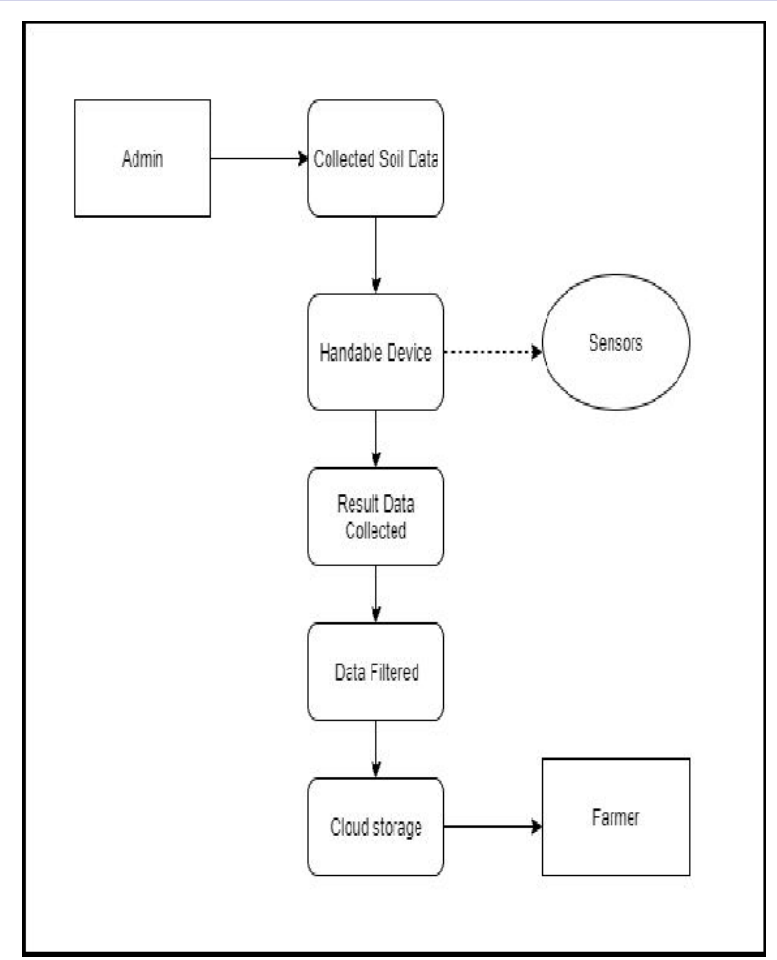

Fig. 8. Data Flow Diagram

\section{IMPLEMENTATION}

The initial connection of the system where The different sensors like temperature and humidity sensors are connected to the chip using jumping wires.

The NODE MCU chip which consists of Wifi-Module and various other functionalities have been connected. And the systems developed by connection of different hardware devices are being implemented under various different conditions of soil.

\section{A. RESULT:}

Fig. 8. Output For Humidity, Temperature on Mobile Phone

\section{CONCLUSION \& FUTURE SCOPE}

Smart Farming IoT Based Agriculture Stick for Live Monitoring of Temperature and Soil Moisture has been proposed using Node MCU Chip, Wifi Module and various other Hardware Devices. The stick has high efficiency and accuracy in fetching the live data of temperature, humidity and soil moisture. The IOT based Agriculture stick being developed through this paper will help farmers in increasing the agriculture yield and take efficient care of food production as the stick will always provide helping hand to farmers for getting accurate live feed of environmental temperature and soil moisture with accurate results. With the help of these systems various problems faced by farmers in daily life are being solved to a greater extent.

For development in future, it can be enhanced by developing this system for large acres of land. Also the system can be integrated to check the quality of the soil and the growth of crop in each soil. The sensors and microcontroller are successfully interfaced and wireless communication is achieved between various nodes. Future work also includes to focus more on increasing sensors on this stick to fetch more data especially with regard to Pest Control and by also integrating GPS modules in this IoT Stick to enhance this Agriculture IoT Technology to fullfledged Agriculture Precision ready product.

\section{VII.OUTPUT}

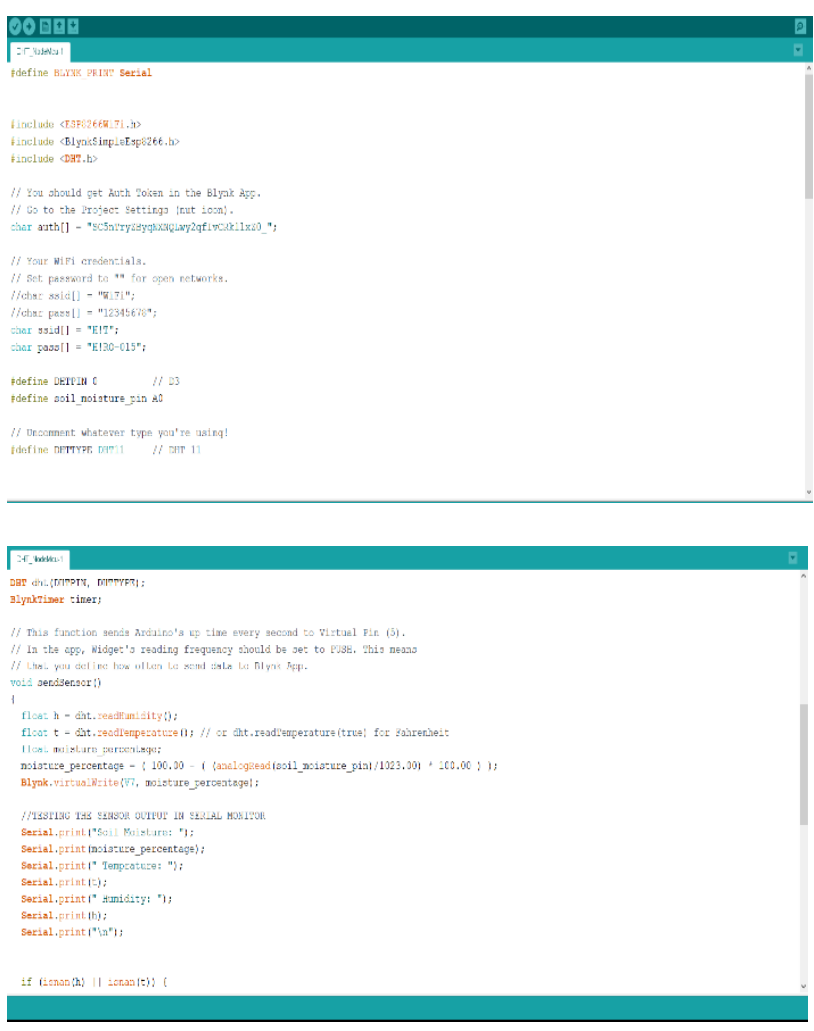



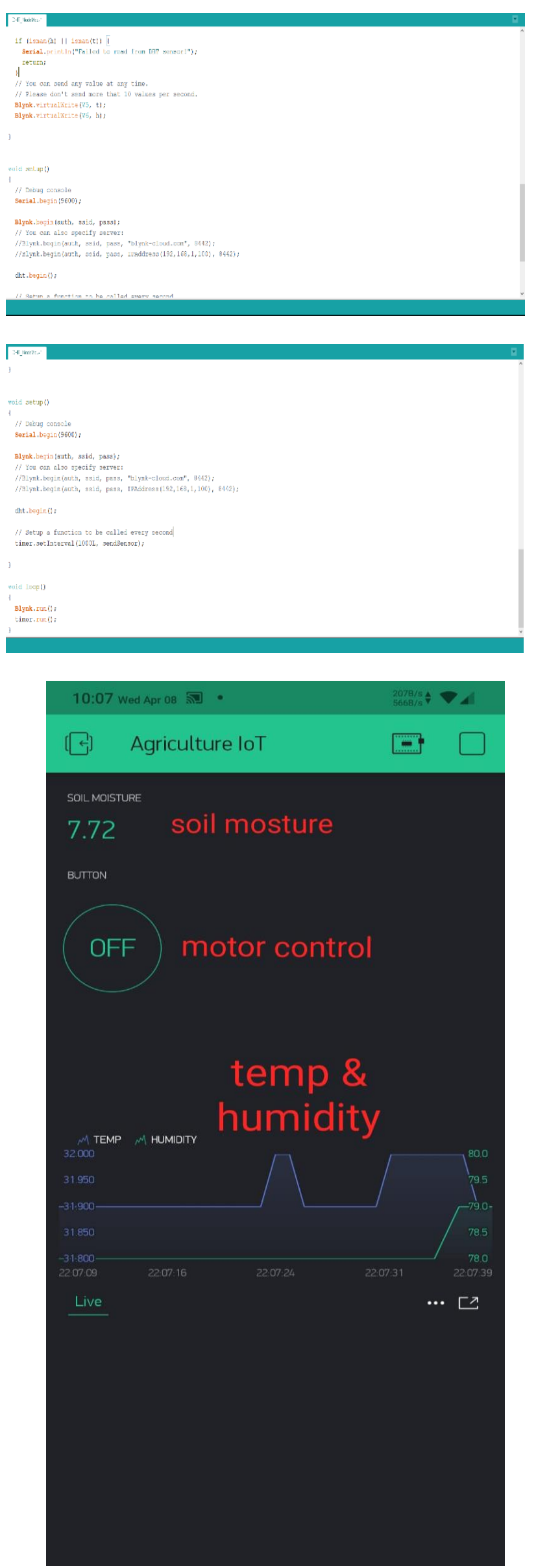

\section{REFERENCES}

[1] K. Lakshmisudha et. al, "Smart Precision Based Agriculture Using Sensors", International Journal of Computer Applications (09758887), Volume 146-No.11, July 2011.

[2] $\mathrm{N}$ Gondchawar \& Dr. R.S.Kawitkar, "IoT Based Smart Agriculture", International Journal of Advanced Research in Computer and Communication Engineering (IJARCCE), Vol.5, Issue 6, June 2016.

[3] M.K.Gayatri et. al, "Providing Smart Agriculture Solutions to Farmers for Better Yielding Using IoT", IEEE International Conference on Technological Innovations in ICT for Agriculture and Rural Development (TIAR 2015).

[4] Chetan Dwarkani et. al, "Smart Farming System Using Sensors for Agricultural Task Automation”, IEEE International Conference on Technological Innovations in ICT for Agriculture and Rural Development (TIAR 2015)

[5] S. R. Nandurkar et. al, "Design and Development of Precision Agriculture System Using Wireless Sensor Network", IEEE International Conference on Automation, Control, Energy and Systems (ACES), 2014.

[6] Joaquín Gutiérrez et. al, "Automated Irrigation System Using a Wireless Sensor Network and GPRS Module", IEEE Transactions on Instrumentation and Measurements, 0018-9456,2013 .

[7] Dr. V.Vidya Devi \& G. M Kumari, "Real- Time Automation and Monitoring System for Modernized Agriculture" ,International Journal of Review and Research in Applied Sciences and Engineering (IJRRASE) Vol3 No.1. PP 7-12, 2013.

[8] Meonghun Lee et. al, "Agricultural Protection System Based on IoT", IEEE 16th International Conference on Computational Science and Engineering, 2013.

[9] Monika Jhuria, "Image Processing for Smart Farming: Detection of Disease and Fruit Grading", IEEE Second International Conference on Image Information Processing (ICIIP), 2013.

[10] Ms. Roopashree V. et. al, "IOT in Indian Agricultural using WSN", In this the user can water fields and protect his crops from anywhere by using GSM technique.

[11] Kim Y., Evans R.G. and Iversen W.M., "Remote Sensing and Control of an Irrigation System Using a Distributed Wireless Sensor Network," Instrumentation and Measurement, IEEE Transactions on, vol.57, no.7, pp.1379-1387, July 2008.

[12] Joaquín G, Juan F, Alejandra N.G, and Miguel Ángel, "Automated Irrigation System Using a Wireless Sensor Network and GPRS Module", IEEE Transactions On Instrumentation and Measurement, Vol.63, no.1, pp.166-176, 2013.

[13] Karandeep K, "Machine Learning : Applications in Indian Agriculture", International Journal of Advanced Research in Computer and Communication Engineering, Vol.5, no.4, pp.342344, 2016.

[14] Kumar R, Singh M .P, Prabhat K, and Singh J.P. "Crop Selection Method to Maximize Crop Yield Rate Using Machine Learning Technique." Proceedings of International Conference on Smart Technologies and Management for Computing, Communication, Controls, Energy and Materials (ICSTM) ,2015.

[15] Koushik Anand, Jayakumar C, Mohana Muthu and Sridhar A, "Automatic Drip Irrigation using Fuzzy Logic and Mobile Technology", Proceedings of Technological Innovation in ICT for Agriculture and Rural Development, 2015.

[16] Suyash S P and Sandeep A T, "Early Detection of Grapes Disease using Machine Learning and IoT", Proceedings of Second International Conference on Cognitive Computing and Information Processing, Mysore, India, 2016.

[17] Yue L, Long M and Ooi S K, "Prediction of Soil Moisture based on Extreme Learning Machine for an Apple Orchard", Proceedings of 3rd IEEE International Conference on Cloud Computing and Intelligent System", Shenzhen, Hong Kong, 2014.

[18] Biswas S, Saunshi A, Sarangi S and Pappula S, "Random Forest based Classification of Diseases in Grapes from Images Captured in Uncontrolled Environment", Proceedings of IET International Conference on Signal Processing, 2016. 